\title{
Prediction of Drug Users Based on Facial Scratching Pattern
}

\author{
https://doi.org/10.3991/ijoe.v17i03.17351 \\ Bagus Priambodo $\left.{ }^{\bowtie}\right)$, Yuwan Jumaryadi, Sarwati Rahayu, Diky Firdaus \\ Universitas Mercu Buana, Jakarta, Indonesia \\ bagus.priambodo@mercubuana.ac.id \\ Muhammad Sobri \\ Universitas Bina Darma, Palembang, Indonesia \\ Zico Pratama Putra \\ Queen Mary University of London, London, United Kingdom
}

\begin{abstract}
The current practice of drug inspection is usually carried out at school or university. This procedure, however, is not effective and efficient, as the urine samples are taken randomly. In many cases, the drug-taking student is not present or evades the urine or hair inspection. A predictive drug user tool is needed, where only suspected student drug users are selected for a urine test. In general, drug abuse constantly causes terrible damage to the skin lesions Since they damage the skin during hallucinations due to the effects of drugs. The Grey Level of Occurrence Matrix (GLCM) is used in this study to discover the scratch pattern. Our proposed GLCM is evaluated with 104 images collected from the Internet. Training data is generated from 88 images of people before and after the drug was collected from the Internet, and we set 16 image faces to test the prediction. The experiment shows that the prediction based on GLCM has better accuracy (81\%) compared with the local binary pattern (LBP) which only reach up to $75 \%$.
\end{abstract}

Keywords - Local binary pattern, grey level co-occurrence matrix, prediction of drug users, face recognition

\section{Introduction}

The recent anti-drug campaign has shown that drug users are becoming thinner due to nutrient deficiencies [1]. This nutrient deficiency can suppress appetite, resulting in low caloric intake and impaired nutrient processing. As a result, the body begins to respond to a decrease caused by a lack of proper nutrition. Persistent drug abuse also leads to severe skin damage due to hallucinations when users scratch their skin [2]. The face may appear unsightly with many pimples. Rough skin scratching often leaves small wounds and scars on the drug user's face.

Facial recognition technology can identify drug addicts in biometric recognition systems, search and index digital image and video databases, including security sys- 
tems, video conferencing, and human interaction with computers. The face recognition classification method is generally divided into three [3], using local features, holistic features, and based on hybrid [4]-[7]. Local binary patterns and grey level of occurrence matrix have been widely used for feature extraction of facial recognition method [8][9].

A previous study that closes with our work is reported from[10] in which they investigated drug users' classification by collecting a dataset of drug users and further developed it by pre-processing drug users' images gathered from the Internet. Further, the total faces are divided into five detection regions for feature computations and classification. Other studies use local binary patterns to extract local features to classify suspect drug users [2].

Our study uses grey-level feature extraction to discover the scratches (wound and scarf) pattern of drug users.

The rest of this paper is structured as follows. The problem description is explained in Section 2. We explain face detection, grey level of occurrence matrix, and the local binary pattern method in Section 3. Our methodology is explained in section 4. In section 5, we explain the result of the experiment and discuss the results. Finally, in section 6 , we conclude the paper.

\section{Problem Description}

A routine drug inspection is the most common practice by checking students' urine or hair to determine the student population's potential drug users. However, when they take urine samples at random, the student taking drugs may not present or may absent to escape the urine or hair inspection. Information technology in computer vision can select students who are suspected of being drug addicts. Students who detect suspected drugs through the system then take urine samples for laboratory analysis. However, a data set is needed to develop a model for identifying drug-dependent users. In general, drug abuse frequently causes terrible damage to skin lesions due to drug abuse hallucinations. There are differences in the facial expressions of people who became drug-dependent before and after drug use. Roughly scratching the skin often leaves the user's face covered in small wounds and scars. Further details are shown in Figure 1[11] [12]. 


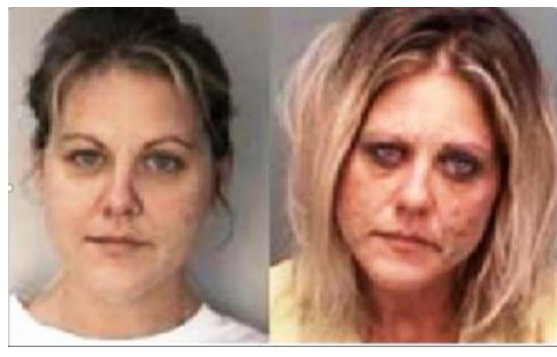

(a) Left, before addicted and right after addicted

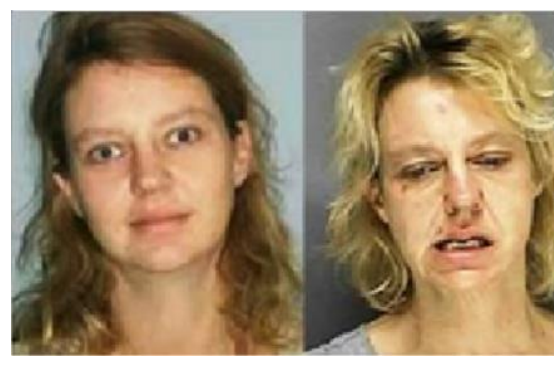

(b) Left, before addicted and right after addicted

Fig. 1. Images of two drugs user face Related Work

In general, three basic steps are used to develop a robust face recognition system:

1) Face detection

2) F extraction

3) Face recognition [3].

\subsection{Face detection}

The face detection process is the first step before performing face recognition. The Viola-Jones algorithm [13], [14] is the most commonly used face detection algorithm. In our study, we use the Adaboost classifier with Haar as a method for face detection.

\subsection{Gray-level co-occurrence matrix}

Gray-level co-occurrence matrix (GLCM) refers to a common method for describing texture by studying grayscale's spatial correlation characteristics. GLCM is obtained by statistically detecting a state in which two pixels have certain distances on the image; each has a certain grayscale level [15].

Contrast is an indicator of the intensity between one matrix value and its neighbour over the entire matrix [16]. Contrast is calculated using equation (1), and the correlation of a matrix value to its neighbour is given by equation (2). Homogeneity describes the closeness of the elements' distribution in the GLCM. It is given by equation (4). Energy is the sum of squared elements in normalized GLCM. It is given by equation (3). In this study, to determine the vertical scratch pattern in the drug user face, we set our GLCM degree as $90^{\circ}$.

$$
\begin{aligned}
& \text { Contrast }=\sum_{i, j}|i-j|^{2} p(i, j)^{2} \\
& \text { Correlation }=\frac{(i-\mu i)(j-\mu j) p(i, j)}{\sigma_{i} \sigma_{j}}
\end{aligned}
$$




$$
\begin{gathered}
\text { Energy }=\sum_{i, j} p(i, j)^{2} \\
\text { Homogeneity }=\sum_{i, j} \frac{(j-\mu j) p(i, j)}{1+|i-j|}
\end{gathered}
$$

\subsection{Local binary pattern}

The genuine local binary pattern algorithm [17] encodes an image's pixels with decimal numbers called Local Binary Patterns or LBP codes. The local binary pattern is applied to face recognition after a list of local binary patterns is obtained. This method encodes the local structure around each pixel, as shown in Figure 2. Each pixel is compared with its eight neighbours in a $3 \times 3$ neighbourhood by comparing the pixel value with the central pixel. The value less than the central pixel is encoded as 0 and the others as 1 . A binary number is generated by merge all these binary codes clockwise begin from the top left, as shown in Figure 2. These binary numbers are called local binary patterns. A histogram example is shown in Figure 3.

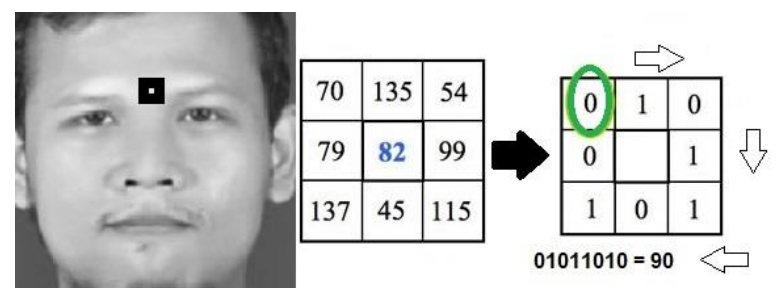

Fig. 2. Illustration of local binary pattern algorithm

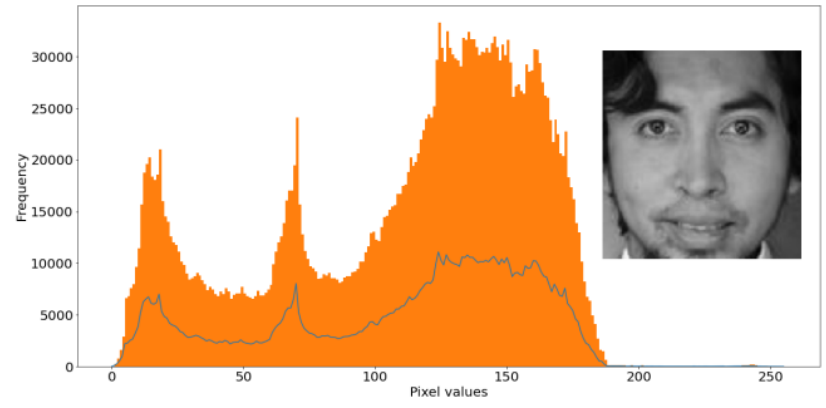

Fig. 3. Example of histogram obtained from image faces

Finally, there is a histogram for each face in each training data set. In other words, for every $\mathrm{N}$ number of images in the training data set, the LBP extracts the $\mathrm{N}$ number of histograms based on the training data and stores them for the recognition process. The algorithm then tracks which histogram is associated with this individual. 


\section{$3 \quad$ Methodology}

Our methodology is explained in figure 4, description for each step is explained below in section $4.1-4.4$.

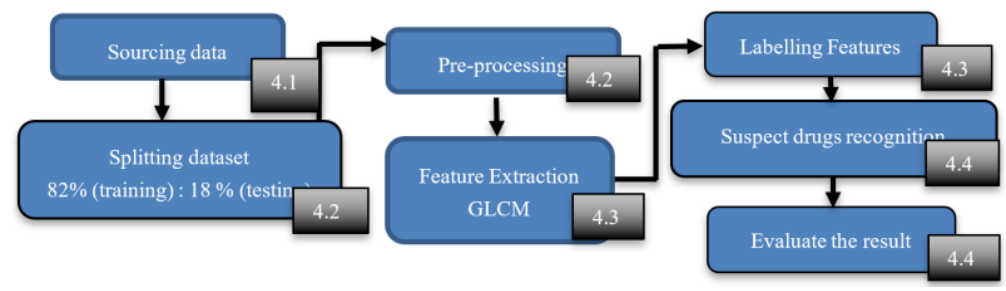

Fig. 4. Methodology to predict suspect drug user

There are 104 images collected from the internet, which is people's images before and after taking drugs. The images were taken from rehabs.com [11] and dailymail.co.uk [12], Internet Fox 24 news [18] and Katy magazine news [19].

\subsection{Splitting dataset and pre-processing}

We split the dataset, eighty-eight images for training and six teen images for testing. The eighty-eight images were pre-processed into grayscale facial images before and after they became drug users. The first is negative data, which are people's images before and after taking drugs. The second is positive data, people images after they became addicted as drug users. Negative data are shown in Figure 5, and positive data in Figure 6.
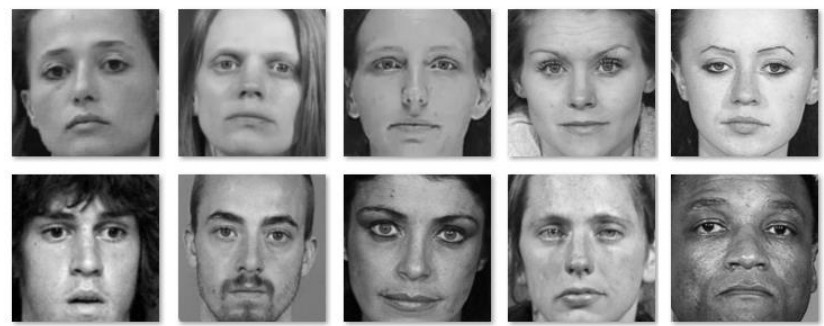

Fig. 5. Image of peoples before they became addicted to drugs (negative data) 


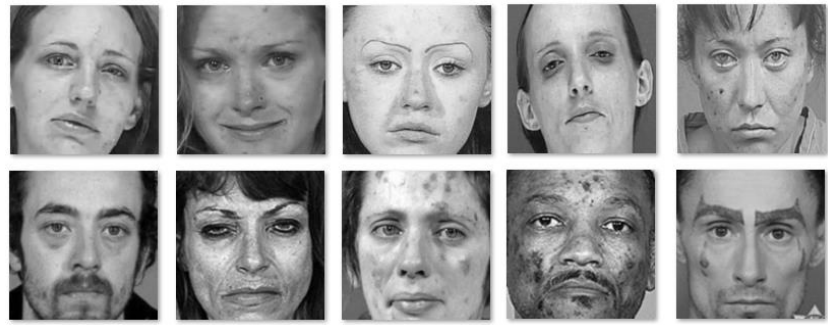

Fig. 6. Image of peoples after became addicted to drugs (positive data)

For testing we set 16 image faces to evaluate the prediction result, as shown in Figures 7 and 8. Positive data image is taken from Internet Fox 24 news [18] and Katy magazine news [19].
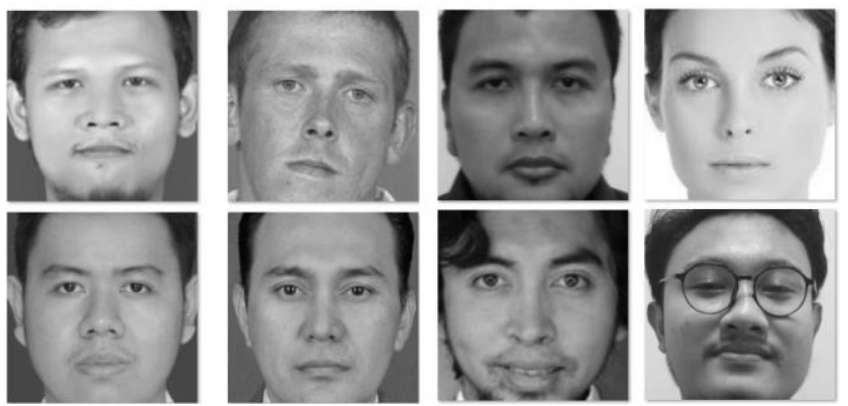

Fig. 7. Image test of negative data after pre-processing
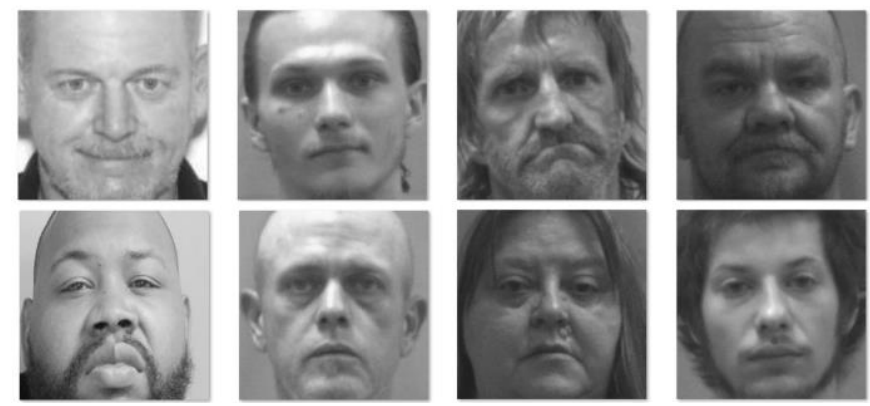

Fig. 8. Image test of positive data after pre-processing

\subsection{Feature extraction and labelling the extracted feature}

The image then extracted using Gray level co-occurrence matrix. There is three possible way to scratch in the face, that is vertical and diagonal way, as explain in figure 9. Grey level co-occurrence matrix is utilized to extract the pattern in three possible degree $\left(135^{\circ}, 90^{\circ}, 45^{\circ}\right)$. 


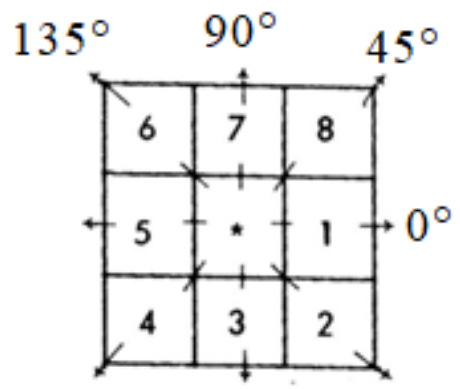

Fig. 9. Three possible way drugs user scratching their faces

For comparison, we evaluate three different neighbourhood sizes of local binary pattern to extract feature of face the variable, explained in figure 10.

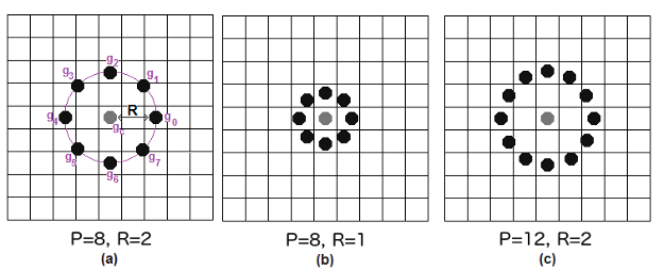

Fig. 10.Variable neighbourhood sizes in local binary pattern, point and radius

\subsection{Suspect drug recognition and evaluation}

Euclidean distance classifier is then used to classify the test image with the training data, Euclidean distance is expressed in (5).

$$
d(x, y)=\sqrt{\sum_{i}^{n}\left(x-y_{i}\right)^{2}}
$$

To evaluate the classification result, the confusion matrix is constructed as shown in table 1 .

Table 1. The confusion matrix

\begin{tabular}{|l|l|l|}
\hline & \multicolumn{1}{|c|}{ Negative (-) } & \multicolumn{1}{c|}{ Positive (+) } \\
\hline Negative (-) & (TN)True-Negative (-) & (FP)False-Positive (+) \\
\hline Positive (+) & (FN)False-Negative (-) & (TP)True-Positive (+) \\
\hline
\end{tabular}

Finally, the classification accuracy for True-Negative (TP), False-Negative (FN), False-Positive (FP), and True-Positive (TP) is expressed in (6).

$$
\text { Accuracy }=(T P+T N) /(T P+F P+T N+F N)
$$




\section{$4 \quad$ Result and Discussion}

The result of prediction using GLCM and local binary patterns is shown in table 2 .

Table 2. The confusion matrix table of the prediction result with each point $(\mathrm{P})$ and radius $(\mathrm{R})$

\begin{tabular}{|c|c|c|c|c|c|c|c|c|c|c|c|c|}
\hline & \multicolumn{6}{|c|}{ Gray level co-occurrence matrix } & \multicolumn{6}{|c|}{ Local binary pattern } \\
\hline & \multicolumn{2}{|c|}{$135^{\circ}$} & \multicolumn{2}{|c|}{$90^{\circ}$} & \multicolumn{2}{|c|}{$45^{\circ}$} & \multicolumn{2}{|c|}{$P=8 R=1$} & \multicolumn{2}{|c|}{$P=8 R=2$} & \multicolumn{2}{|c|}{$P=12 R=2$} \\
\hline & $(-)$ & $(+)$ & $(-)$ & $(+)$ & $(-)$ & $(+)$ & $(-)$ & $(+)$ & $(-)$ & $(+)$ & $(-)$ & $(+)$ \\
\hline$(-)$ & 5 & 3 & 8 & 0 & 5 & 3 & 4 & 4 & 6 & 2 & 7 & 1 \\
\hline$(+)$ & 5 & 3 & 3 & 5 & 6 & 2 & 3 & 5 & 3 & 5 & 3 & 5 \\
\hline
\end{tabular}

Based on the confusion matrix, we obtained the accuracy of prediction using GLCM with $90^{\circ}$ (GLCM with direction 90 degree) is $81 \%$, and using local binary pattern with point $=12$ and radius $=2(\mathrm{LBP} P=12 \mathrm{R}=2)$ is $75 \%$, as shown in Figure 11. It is more likely we would find 90-degree pattern than any other pattern for scratch.

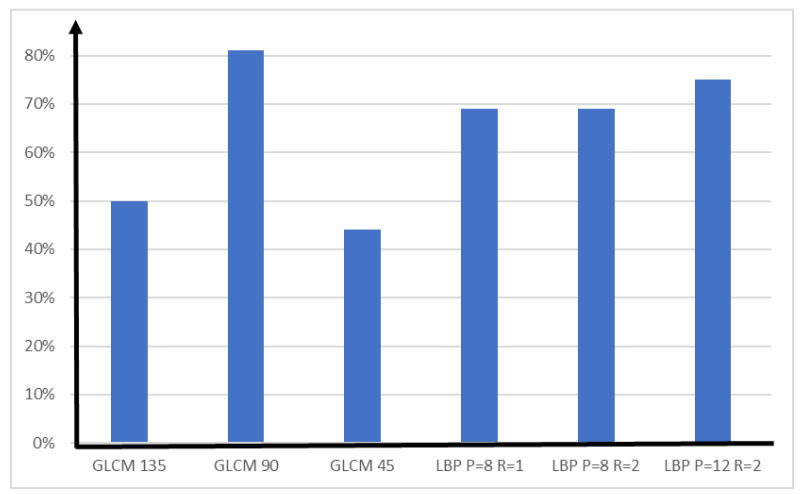

Fig. 11.The result of prediction accuracy between Grey level of co-occurrence matrix (GLCM) and local binary pattern (LBP) with each point (P) and radius (R)

\section{Conclusion}

Our study's main objective is to investigate the scratch pattern on drug users' faces to identify the suspects. Grey level of co-occurrence matrix is used to learn the drugs user scratch pattern. Training images are gathered from the Internet based on $88 \mathrm{im}$ ages before and after becoming drug users. The experimental result using 16 test data show that prediction using GLCM with direction $90^{\circ}$ reaches $81 \%$, it is more likely we would find 90-degree pattern than any other pattern for scratch. Using GLCM has a better performance compared with using local binary patterns, which performs at best to $75 \%$. 


\section{Acknowledgement}

The authors would like to thank Universitas Mercu Buana for funding this research.

\section{$7 \quad$ References}

[1] S. Ali et al., "Early detection of illicit drug use in teenagers," Innov. Clin. Neurosci., vol. 8, no. 12, pp. 24-28, 2011.

[2] B. Priambodo, Y. Jumaryadi, and Z. P. Putra, "Comparison of Local Binary Pattern and Eigenfaces for Predict Suspect Positive Drugs," in 2020 2nd International Conference on Broadband Communications, Wireless Sensors and Powering (BCWSP), 2020, pp. 64-67, https://doi.org/10.1109/bcwsp50066.2020.9249405

[3] Y. Kortli, M. Jridi, A. Al Falou, and M. Atri, "Face recognition systems: A survey," Sensors (Switzerland), vol. 20, no. 2, 2020, https://doi.org/10.3390/s20020342

[4] B. Priambodo, A. Ahmad, and R. A. Kadir, "Prediction of average speed based on relationships between neighbouring roads using K-NN and neural network," Int. J. online Biomed. Eng., vol. 16, no. 1, pp. 18-33, 2020, https://doi.org/10.3991/ijoe.v16i01.11671

[5] D. Firdaus, B. Priambodo, and Y. Jumaryadi, "Implementation of push notification for business incubator," Int. J. online Biomed. Eng., vol. 15, no. 14, pp. 42-53, 2019, https://doi.org/10.3991/ijoe.v15i14.11357

[6] R. Jafri and H. R. Arabnia, "A Survey of Face Recognition Techniques," J. Inf. Process. Syst., vol. 5, no. 2, pp. 41-68, 2009, doi: 10.3745/JIPS.2009.5.2.041.

[7] Z. P. Putra, D. Setiawan, B. Priambodo, and M. D. Anasanti, "Point estimation with markers for effective mobile auditory graphs," Int. J. Emerg. Technol. Learn., vol. 15, no. 8, pp. 116-129, 2020, https://doi.org/10.3991/ijet.v15i08.12347

[8] I. Nurhaida, H. Wei, R. A. M. Zen, R. Manurung, and A. M. Arymurthy, "Texture fusion for batik motif retrieval system," Int. J. Electr. Comput. Eng., vol. 6, no. 6, pp. 3174-3187, 2016, https://doi.org/10.11591/ijece.v6i6.12049

[9] N. S. Fatonah, H. Tjandrasa, and C. Fatichah, "Identification of acute lymphoblastic leukemia subtypes in touching cells based on enhanced edge detection," Int. J. Intell. Eng. Syst., vol. 13, no. 4, pp. 204-215, 2020, https://doi.org/10.22266/ijies2020.0831.18

[10] D. Yadav, N. Kohli, P. Pandey, R. Singh, M. Vatsa, and A. Noore, "Effect of illicit drug abuse on face recognition," 2016, https://doi.org/10.1109/wacv.2016.7477556

[11] "Before \& After Drugs (Meth)," Rehabs.com. https://www.rehabs.com/explore/methbefore-and-after-drugs/infographic.php (accessed Jul. 25, 2020).

[12] K. Lyons, "Ravaged by drugs: Shocking before and after pictures reveal devastating physical toll of meth addiction," dailymail.co.uk, 2014. https://www.dailymail.co.uk/news/ article-2589612/Shocking-images-devastating-physical-toll-drugs-take.html (accessed Jul. 25, 2020).

[13] P. Viola and M. Jones, "Robust real-time face detection,” Int. J. Comput. Vis., vol. 57, no. 2, pp. 137-154, 2004.

[14] P. Viola and M. Jones, "Rapid Object Detection Using a Boosted Cascade of Simple Features," 2001.

[15] P. Shan, "Image segmentation method based on K-mean algorithm," Eurasip J. Image Video Process., vol. 2018, no. 1, 2018, https://doi.org/10.1186/s13640-018-0322-6 
[16] A. Suresh and K. L. Shunmuganathan, "Image texture classification using gray level cooccurrence matrix based statistical features,” Eur. J. Sci. Res., vol. 75, no. 4, pp. 591-597, 2012.

[17] D. Huang, C. Shan, M. Ardabilian, Y. Wang, and L. Chen, "Local binary patterns and its application to facial image analysis: A survey," IEEE Trans. Syst. Man Cybern. Part C Appl. Rev., vol. 41, no. 6, pp. 765-781, 2011, https://doi.org/10.1109/tsmcc.2011. $\underline{2118750}$

[18] K. Jordan, "Police: More than 20 arrested for meth operation in River Valley," Fox24, 2019. https://www.nwahomepage.com/myfox 24/police-more-than-20-arrested-for-methoperation-in-river-valley-2/.

[19] N. C. Clark, "Rap Artist Arrested on Drug Charges in Katy Area," KATY MAGAZINE NEWS, 2020. https://www.katymagazineonline.com/post/rap-artist-arrested-on-drugcharges-in-katy-area (accessed Jul. 25, 2020).

\section{Authors}

Bagus Priambodo, Yuwan Jumaryadi, Sarwati Rahayu and Diky Firdaus are senior lecturers at Faculty of Computer Science, Universitas Mercu Buana, Jakarta, Indonesia. Their research interest lies in the area of machine learning, human computer interaction, computer vision, and big data analytics. Email: bagus.priambodo@mercubuana.ac.id, yuwan.jumaryadi@mercubuana.ac.id, sarwati@mercubuana.ac.id, diky.firdaus@mercubuana.ac.id

Muhammad Sobri works for Universitas Bina Darma, Palembang, in Indonesia.

Zico Pratama Putra a lecturer for School of Electronic Engineering and Computer Science, Queen Mary University of London, London, in United Kingdom. His research interest is in Human Computer Interaction, machine learning, and cloud computing. Email: z.putra@qmul.ac.uk

Article submitted 2020-07-29. Resubmitted 2021-01-07. Final acceptance 2021-01-08. Final version published as submitted by the authors. 